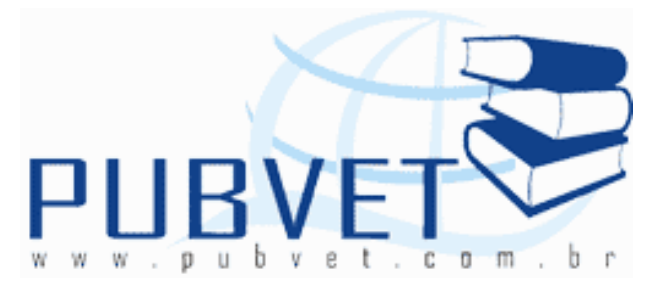

PUBVET, Publicações em Medicina Veterinária e Zootecnia.

\title{
Quantificação de coliformes totais e termotolerantes em queijo Minas Frescal artesanal
}

Renata Marques Ferreira ${ }^{1}$; Janise de Castro Moraes Spini ${ }^{1}$; Leonardo Gomes Carrazza²; Driele Schneidereit Sant'ana²; Millene Torres de Oliveira²Luana Ribeiro Alves²; Thaís Gomes Carrazza ${ }^{3}$

${ }^{1}$ Médica Veterinária.

2 Mestrando do Programa de Pós-Graduação em Ciências Veterinárias da Universidade Federal de Uberlândia - UFU.

${ }^{3}$ Graduanda do curso de Medicina Veterinária da Universidade Federal de Uberlândia - UFU.

\section{Resumo}

Foram analisadas vinte amostras de queijo Minas Frescal obtidas em feiraslivres da cidade de Uberlândia-MG, durante o período de outubro a novembro de 2006. A análise microbiológica constituiu-se da contagem de coliformes totais e fecais ou termotolerantes, através do NMP (Número Mais Provável), onde 14 das amostras analisadas (70\%) apresentaram NMP de coliformes totais superiores a $10^{3} \mathrm{NMP} / \mathrm{g}$ e 16 das amostras analisadas (80\%) apresentaram NMP de coliformes termotolerantes superiores a $10^{2} \mathrm{NMP} / \mathrm{g}$. De acordo com os resultados, os queijos artesanais comercializados apresentaram condições higiênico-sanitárias insatisfatórias, o que representa um risco à saúde dos consumidores.

Palavras-chave: coliformes fecais; leite; higiene-sanitária 
FERREIRA, R.M. et al. Quantificação de coliformes totais e termotolerantes em queijo Minas

Frescal artesanal. PUBVET, Londrina, V. 5, N. 5, Ed. 152, Art. 1022, 2011.

\title{
Measurement of total and fecal coliforms in Minas cheese artisan
}

\begin{abstract}
Were analyzed twenty samples of cheese obtained from street vendors, in the city of Uberlândia-MG, during the period from October to November 2006. Microbiological analysis consisted of counts of total and fecal coliforms or thermotolerant, through the MPN (Most Probable Number), where 14 of the samples analyzed (70\%) had MPN of total coliforms above $10^{3} \mathrm{MPN} / \mathrm{g}$, and 16 samples analyzed (80\%) had MPN of thermotolerant coliforms above $10^{2}$ MPN / g. This indicates that the artisan cheeses sold had inadequate sanitary conditions, which represents a health risk to consumers.
\end{abstract}

Keywords: fecal coliforms, milk, sanitary hygiene

\section{INTRODUÇÃO}

O queijo Minas artesanal é consumido por diferentes classes sociais, tendo em vista seu preço acessível, embora o tipo de processamento seja o responsável por contaminações normalmente encontradas (SILVA, CASTRO, 1995). É um queijo de massa crua, com alto teor de umidade, não maturado, de consumo imediato. Possui baixo custo decorrente da simplicidade de sua produção, que, na maioria das vezes, é feito de forma caseira, com utilização de leite cru, sem higiene adequada e falta de condições apropriadas no transporte e estocagem. Tais fatores contribuem para o crescimento microbiano, comprometendo a qualidade do produto e conseqüentemente, prejudicando a saúde do consumidor (RODRIGUES et al., 1995).

Esse queijo geralmente é comercializado em embalagens plásticas comuns, amarradas ou fechadas com fechos metálicos. Durante sua comercialização, essa embalagem se apresenta com um depósito de soro ou exsudato decorrente do excesso de umidade, que além de proporcionar um aspecto pouco atraente ao produto, favorece a proliferação de microrganismos 
FERREIRA, R.M. et al. Quantificação de coliformes totais e termotolerantes em queijo Minas Frescal artesanal. PUBVET, Londrina, V. 5, N. 5, Ed. 152, Art. 1022, 2011.

contaminantes, responsáveis pelo sabor e odor desagradáveis, reduzindo a vida útil do produto, mesmo em temperaturas adequadas.

O leite é um alimento universalmente conhecido pelo seu alto valor nutricional. Porém, é capaz de veicular inúmeros microrganismos, pois mesmo que a legislação brasileira determine que todo leite para ser comercializado deva passar por tratamento térmico, observa-se ainda a comercialização do "leite informal", sem qualquer tipo de inspeção, e sem garantia de pasteurização.

O queijo Minas Frescal artesanal, é o principal queijo produzido com leite cru e é geralmente comercializado de forma informal, em feiras, mini-mercados e até mesmo nas próprias fazendas produtoras, oferecendo um grande risco à saúde devido á possível ingestão de elevada carga bacteriana e microrganismos patogênicos(OLIVAL, A.A. et al., 2002).

A venda do queijo Minas Frescal produzido artesanalmente tem sido realizada abertamente em nosso meio com a utilização do leite cru. Devido a isso, a presença de coliformes totais e fecais acima do índice máximo permitido, além de evidenciar a ineficiência ou ausência de controle da matéria prima, do processo de fabricação e do produto acabado, indica também a possibilidade da vinculação de patógenos responsáveis pela ocorrência de surtos de gastroenterites (ALMEIDA FILHO, NADER FILHO, 2002).

Alimentos que requerem considerável manipulação durante o preparo e a temperatura de refrigeração é inadequada, são passíveis de causar intoxicação alimentar. O leite utilizado na fabricação de queijos deve apresentar boa qualidade e ser pasteurizado, para reduzir os riscos de contaminações. A pasteurização tem a finalidade de eliminar os microrganismos patogênicos do leite, mantendo-se ao máximo as características organolépticas do leite.

Nas análises de queijo Minas Frescal artesanal, freqüentemente são encontrados Coliformes totais e fecais. É necessário ressaltar que estes últimos são encontrados em muitos alimentos adquiridos pelos consumidores, mas sua nocividade decorre da quantidade em que são encontrados nos alimentos. Em níveis acima do que se pode considerar normal, e que a lei nacional impõe 
FERREIRA, R.M. et al. Quantificação de coliformes totais e termotolerantes em queijo Minas Frescal artesanal. PUBVET, Londrina, V. 5, N. 5, Ed. 152, Art. 1022, 2011.

observância através de seus órgãos, como o de vigilância sanitária, as bactérias agridem o corpo humano causando graves intoxicações.

As bactérias do grupo coliforme são consideradas como principais agentes contaminantes, estando associados á deterioração de queijos, causando fermentações anormais e estufamento precoce dos produtos, além de intoxicações alimentares (OKURA, M.H. et al.,2002). Por estes motivos, devem ser obedecidas as normas estabelecidas para fabricação, além de serem adotadas práticas de higiênie-sanitária, de forma a prevenir possível contaminação ou recontaminação do produto.

De acordo com a legislação, os padrões microbiológicos para Queijo Minas Frescal são: número mais provável (NMP) máximo de $10^{4} / \mathrm{g}$ para coliformes totais e $5 \times 10^{3} / \mathrm{g}$ para coliformes fecais.

Os coliformes fecais, também chamados de termotolerantes, são bactérias que possuem origem nas fezes do homem ou animais de sangue quente, podendo causar diarréia e outros distúrbios intestinais. Essas bactérias são consideradas os principais agentes contaminantes, cuja presença em alimentos é indicativa de contaminação de origem fecal evidenciando péssimas condições de higiene. Além disso, possibilita a veiculação de outros microrganismos patogênicos ao homem, sendo responsáveis também pela deterioração de queijos, ocasionando fermentações anormais e estufamento precoce (ALMEIDA FILHO, NADER FILHO, 2002).

A ocorrência de elevado número de coliformes indica processamento inadequado ou possível recontaminação pós-processamento, podendo ser proveniente da própria matéria-prima, equipamentos mal higienizados, manipulação sem cuidados higiênicos ou proliferação microbiana devido a condições desfavoráveis de armazenamento, que permitem a multiplicação de microrganismos patogênicos ou toxigênicos (PELCZAR et al. 1996).

A Escherichia coli enterotoxigênica é a causa mais comum da "diarréia do viajante". Algumas cepas, ao serem ingeridas com alimentos, crescem no intestino e produzem toxinas que originam hipersecreção no intestino delgado; a luz intestinal é distendida pelo líquido, provocando hipermotilidade e diarréia 
FERREIRA, R.M. et al. Quantificação de coliformes totais e termotolerantes em queijo Minas Frescal artesanal. PUBVET, Londrina, V. 5, N. 5, Ed. 152, Art. 1022, 2011.

durando por volta de um a três dias. O período de incubção é de 24 a 72 horas, podendo causar diarréia, vômitos, mas não apresenta febre (LOGUERCIO, ALEIXO, 2001).

Já os Coliformes totais, são compostos por bactérias da família Enterobacteriaceae, capazes de fermentar lactose produzindo ácido e gás num período de $24-48$ horas a $32-37^{\circ} \mathrm{C}$. São bacilos Gram negativos, sendo aeróbios ou anaeróbios facultativos. A presença de coliformes totais e fecais em alimentos processados indica que a matéria prima pode estar contaminada, utensílios e equipamentos utilizados na fabricação podem estar mal higienizados, ou pode haver falta de higiene por parte dos manipuladores do produto (RITTER et al., 2001). Além de caracterizar contaminação pósprocesso, evidenciando práticas de higiene e sanitização aquém dos padrões requeridos para o processamento de alimentos (SILVA et al, 1997).

Nesse sentido, essa pesquisa foi realizada com o intuito de determinar a presença de coliformes fecais e coliformes totais, por meio da avaliação da qualidade higiênico-sanitária de queijos Minas Frescal artesanal, comercializado nas feiras-livres da cidade de Uberlândia-MG.

\section{MATERIAL E MÉTODOS}

Foram obtidas 20 amostras de Queijo Minas artesanal, de feiras livres, no município de Uberlândia-MG, em temperatura ambiente, na própria embalagem do comerciante. As amostras foram transportadas, em caixas isotérmicas, para o Laboratório de Controle de Qualidade e Segurança Alimentar, da Faculdade de Medicina Veterinária, da Universidade Federal de Uberlândia, onde foram analisadas.

\section{Preparo das amostras}

Foram pesadas assepticamente $10 \mathrm{~g}$ de amostra em um frasco com $90 \mathrm{~mL}$ de salina estéril, homogenizando a seguir (diluição $10^{-1}$ ). 
FERREIRA, R.M. et al. Quantificação de coliformes totais e termotolerantes em queijo Minas Frescal artesanal. PUBVET, Londrina, V. 5, N. 5, Ed. 152, Art. 1022, 2011.

\section{Determinação do Número Mais Provável (NMP/g) de coliformes totais}

Foram semeadas três séries de três tubos de ensaio contendo cada um $10 \mathrm{~mL}$ de caldo lauril sulfato triptose (DIFCO), com $1 \mathrm{~mL}$ das diluições $10^{-1}, 10^{-2}$ e $10^{-3}$ homogeneizando e incubando os tubos a $45^{\circ} \mathrm{C}$ por 24 horas. A presença de coliformes foi observada pela formação de gás nos tubos de Durhan e através de repicagem dos positivos por alçada em caldo verde brilhante, onde foram incubados a $37^{\circ} \mathrm{C}$ por 24 horas. Os resultados foram analisados pela tabela de Número Mais Provável de Hoskins (SIQUEIRA, 1995).

\section{Determinação do Número Mais Provável (NMP/g) de coliformes fecais}

Os tubos positivos, com presença de gás no caldo lauril sulfato de sódio, obtidos no teste presuntivo, foram repicados, por alçada, para tubos contendo caldo EC (DIFCO), com tubos de fermentação de Durhan, e incubados a $45^{\circ} \mathrm{C}$ por 24 horas. A presença de coliformes termotolerantes foi confirmada pela formação de gás nos tubos. O Número Mais Provável de coliformes fecais foi calculado com auxílio da tabela de Hoskins (SIQUEIRA, 1995).

\section{RESULTADOS E DISCUSSÕES}

Os resultados obtidos, após a realização das análises microbiológicas nas vinte amostras de queijo Minas Frescal artesanal, estão demonstrados na Tabela 1.

A análise dos coliformes totais apresentou valores mínimos e máximos de $<3,0 \times 10^{1}$ e $\geq 1,1 \times 10^{4} \mathrm{NMP} / \mathrm{g}$, respectivamente. Para a análise de coliformes fecais os valores mínimos e máximos foram $<2,0 \times 10^{2}$ e $\geq 1,1 \times$ $10^{4} \mathrm{NMP} / \mathrm{g}$, respectivamente. Das 20 amostras analisadas, 14 delas (70\%) apresentaram contagens acima de $10^{3} \mathrm{NMP} / \mathrm{g}$ para coliformes totais, ou seja, 
FERREIRA, R.M. et al. Quantificação de coliformes totais e termotolerantes em queijo Minas Frescal artesanal. PUBVET, Londrina, V. 5, N. 5, Ed. 152, Art. 1022, 2011.

acima do padrão exigido, e 16 amostras (80\%), apresentaram número de coliformes termotolerantes superiores a $10^{2} \mathrm{NMP} / \mathrm{g}$ (BRASIL, 2004).

Tabela 1. Representação dos resultados obtidos após as análises microbiológicas.

\begin{tabular}{lcc}
\hline $\begin{array}{l}\text { Queijo } \\
\text { (no da amostra) }\end{array}$ & $\begin{array}{c}\text { ColiformesTotais } \\
(\mathrm{NMP} / \mathrm{g})\end{array}$ & $\begin{array}{c}\text { Coliformes Fecais } \\
(\mathrm{NMP} / \mathrm{g})\end{array}$ \\
\hline 01 & $2,1 \times 10^{3}$ & $4,6 \times 10^{3}$ \\
02 & $1,1 \times 10^{4}$ & $1,1 \times 10^{4}$ \\
03 & $1,1 \times 10^{4}$ & $1,1 \times 10^{4}$ \\
04 & $9,3 \times 10^{2}$ & $9,3 \times 10^{2}$ \\
05 & $1,1 \times 10^{4}$ & $1,1 \times 10^{4}$ \\
06 & $2,7 \times 10^{2}$ & $2,7 \times 10^{2}$ \\
07 & $9,3 \times 10^{2}$ & 0 \\
08 & $1,1 \times 10^{4}$ & $>1,1 \times 10^{4}$ \\
09 & $1,1 \times 10^{4}$ & $1,1 \times 10^{4}$ \\
10 & $1,1 \times 10^{4}$ & $1,1 \times 10^{4}$ \\
11 & $1,1 \times 10^{4}$ & $2,0 \times 10^{2}$ \\
12 & $1,4 \times 10^{2}$ & 0 \\
13 & $1,1 \times 10^{4}$ & $1,1 \times 10^{4}$ \\
14 & $3,0 \times 10$ & 0 \\
15 & 0 & 0 \\
16 & $1,1 \times 10^{4}$ & $1,1 \times 10^{4}$ \\
17 & $1,1 \times 10^{4}$ & $1,1 \times 10^{4}$ \\
18 & $1,1 \times 10^{4}$ & $1,1 \times 10^{4}$ \\
19 & $1,1 \times 10^{4}$ & $2,9 \times 10^{3}$ \\
20 & $1,1 \times 10^{4}$ & $1,1 \times 10^{4}$ \\
\hline Variação & $<3,0 \times 10$ & $2,0 \times 10^{2}$ \\
& $21,1 \times 10^{4}$ & $a$ \\
\hline Padrão Federal & Máximo & $1,1 \times 10^{4}$ \\
(Brasil, 2004) & $10^{3}$ & Máximo \\
\hline
\end{tabular}


FERREIRA, R.M. et al. Quantificação de coliformes totais e termotolerantes em queijo Minas Frescal artesanal. PUBVET, Londrina, V. 5, N. 5, Ed. 152, Art. 1022, 2011.

Tais dados sugerem que os queijos Minas Frescal artesanal podem ter sido contaminados durante a obtenção do leite na fazenda, no processamento e manipulação inadequados e/ou pelas embalagens mal higienizadas, além de serem mantidas à temperatura ambiente (inadequada) no comércio.

Os coliformes totais em números elevados podem deteriorar o produto, além de serem indicativos de condições higiênicas de produção precárias. Os coliformes fecais ou termotolerantes nos alimentos fornecem informações sobre as condições higiênicas do produto, isso porque fazem parte de um grupo de bactérias que habitam o trato intestinal do homem e de outros animais e contaminam o alimento com as fezes (FRANCO, LANDGRAF, 1996).

A presença de coliformes totais e fecais nos queijos Minas Frescal artesanal, pode indicar contaminação, dos utensílios e equipamentos e também falta de higiene dos manipuladores do produto.

\section{CONCLUSÃO}

A qualidade higiênico-sanitária dos queijos Minas frescal analisados, produzidos artesanalmente e comercializados em feiras-livres, é muito precária, constituindo riscos à saúde do consumidor devido a qualidade inadequada das matérias-primas e/ou condições impróprias de processamento, estocagem e comercialização.

\section{REFERÊNCIAS BIBLIOGRÁFICAS}

ALMEIDA FILHO, E.S., NADER FILHO, A. Ocorrência de coliformes fecais e Escherichia coli em queijo Minas Frescal de produção artesanal, comercializado em Poços de Caldas, Minas Gerais. Revista Higiene Alimentar, v.16, n. 102/103, p. 71-73, nov. -dez., 2002.

BRASIL. Ministério da Agricultura, Pecuária e do Abastecimento.Regulamento Técnico para Fixação de Identidade e Qualidade do Queijo Minas Frescal. Diário Oficial da União, BrasíliaDF, n.4, seção 1, p.5, 1 de março de 2004.

FRANCO, B.D.G.M, LANDGRAF, M. Microbiologia dos Alimentos. São Paulo: Ed. Atheneu, 182p., 1996. 
FERREIRA, R.M. et al. Quantificação de coliformes totais e termotolerantes em queijo Minas Frescal artesanal. PUBVET, Londrina, V. 5, N. 5, Ed. 152, Art. 1022, 2011.

LOGUERCIO, A. P., ALEIXO, J.A.G. Microbiologia do queijo tipo Minas Frescal produzido artesanalmente. Ciência Rural. Santa Maria, vol. 31, n. 6. 2001. Disponível em: http: // www.scielo.br/scielo. php/Ing en. Acesso em :18 de Setembro de 2005.

OKURA, M.H., ARAUJO, P.F., JARDIM, F.B.B., SILVA, R.R., FINZER, J.R.D., FRANZÉ, S.J. Influência da atmosfera modificada sobre a qualidade do queijo Minas Frescal.Revista Higiene Alimentar, v.20, n.143, p.84-91, agosto 2006.

OLIVAL, A.A., SPEXOTO, A.A., CAMPOS, S.F.D., FERREIRA, F., FONSECA, L.F.L., SANTOS, V.M., DIAS, A.R. Hábitos de consumo do leite informal, associados ao risco de transmissão de doenças, no município de Pirassununga-São Paulo. Revista Higiene Alimentar, v.16, n.102/103, p. 35-40, nov.- dez.,2002.

PELCZAR, Jr., M. J., CHAN, E. C. S., KRIEG, N. R. Microbiologia: conceitos e aplicações. V.II, $2^{a}$ ed. São Paulo: Makron Books, parte 2, p. 521, 1996.

RITTER, R., SANTOS,D., BERGMANN,G.P. Análise da qualidade microbiológica do queijo colonial, não pasteurizado, produzido e comercializado por pequenos produtores, no Rio Grande do Sul.Revista Higiene Alimentar, v.15, n.87, p.51-55, 2001.

RODRIGUES, F. T.; VIEIRA, M. D.; SANTOS, J. L.; PIERRE, S. J.; ARAÚJO, W. C.; ANDRADE, N. J.; BRANDÃO, S. C. C. Características microbiológicas de queijo tipo Minas Frescal comercializados em Viçosa-MG. In: XIII CONGRESSO NACIONAL DE LATICÍNIOS, Julho, 1995, Juiz de Fora. Anais... Centro de Ensino e Pesquisa / Instituto de Laticínios Cândido Tostes, 1995. p. 233 a 235.

SILVA, M. C.C.; CASTRO, D. G. Ocorrência de surto de Toxinfecção alimentar causada por queijo tipo Minas. In: XIII CONGRESSO NACIONAL DE LATICÍNIOS, julho 1995, Juiz de Fora. Anais... Centro de Ensino e Pesquisa / Instituto de Laticínios Cândido Tostes, 1995. p. 145 a 147.

SILVA, N., JUNQUEIRA, V. C. A.; SILVEIRA, N. F. A. Manual de métodos de análise microbiológica de alimentos. São Paulo: Livraria Varela, 1997, p.31a 39, 265 a 276.

SIQUEIRA, RS. Manual de microbiologia de alimentos. Serviço de Informação-SPI. Brasília, DF. 1995. 